\title{
Case Report: Mucus plug in bronchus mimicking a bronchial solid foreign body obstruction [version 1; peer review: 2
}

\section{approved]}

\author{
Kiran Devkota (D), Miao He, You Wei Zhang \\ Department of Pediatrics, Renmin Hospital, Hubei University of Medicine, Shiyan, Hubei, 442000, China
}

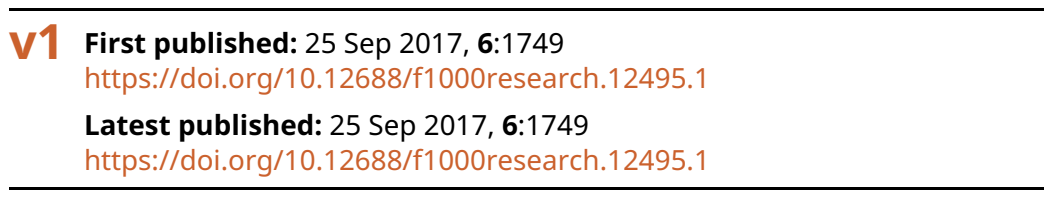

\section{Abstract}

Bronchial foreign body obstruction is common in all clinical settings. Obstruction of the airway due to foreign bodies and foreign body aspiration are major causes of childhood mortality and morbidity, which are a big challenge to manage. Occasionally, bronchial obstruction may be due to mucus plugs or other endogenous factors. Here we describe a case of bronchial obstruction caused by mucus plug formation that was managed conservatively in a one-year old boy. The patient was suffering from a cough and noisy breathing for 2 days prior to coming to our hospital, when he experienced sudden onset of difficulty in breathing and a severe cough. At the time of presentation his vital sign readings were:- HR 186 bpm, RR 46/min, BP $78 / 40 \mathrm{MmHg}$, temp $36.9^{\circ} \mathrm{C}$ and SPO2 68\%. He was given oxygen immediately and nebulization was started. Chest CT scan was performed that suggested the presence of a right bronchial foreign body with right sided obstructive emphysema. The patient was stable with oxygenation and nebulization with ipratropium bromide, albuterol, normal saline and budesonide before the CT scan. Therefore, we conclude that symptoms resembling foreign body obstruction are not always aspirated or inhaled, and sometimes secreted sputum forms a plug, which mimics the symptoms of foreign body obstruction.

\section{Keywords}

foreign body, bronchial obstruction, plastic bronchitis

\section{Open Peer Review \\ Approval Status \\ 1 \\ 2 \\ version 1 \\ 25 Sep 2017

view \\ $\checkmark$ \\ 1. Francesco Menzella ID, Arcispedale Santa \\ Maria Nuova - IRCCS, Reggio Emilia, Italy \\ 2. Peng Hu, The First Affiliated Hospital of \\ Anhui Medical University, Hefei, China \\ Any reports and responses or comments on the article can be found at the end of the article.}


Corresponding author: Kiran Devkota (kirandevkota@gmail.com)

Author roles: Devkota K: Conceptualization, Methodology, Project Administration, Writing - Original Draft Preparation, Writing Review \& Editing; He M: Investigation, Writing - Original Draft Preparation, Writing - Review \& Editing; Zhang YW: Conceptualization, Project Administration, Resources, Supervision, Validation, Writing - Review \& Editing

Competing interests: No competing interests were disclosed.

Grant information: The author(s) declared that no grants were involved in supporting this work.

Copyright: ( 2017 Devkota K et al. This is an open access article distributed under the terms of the Creative Commons Attribution License, which permits unrestricted use, distribution, and reproduction in any medium, provided the original work is properly cited.

How to cite this article: Devkota K, He M and Zhang YW. Case Report: Mucus plug in bronchus mimicking a bronchial solid foreign body obstruction [version 1; peer review: 2 approved] F1000Research 2017, 6:1749 https://doi.org/10.12688/f1000research.12495.1

First published: 25 Sep 2017, 6:1749 https://doi.org/10.12688/f1000research.12495.1 


\section{Introduction}

Obstruction of the airway due to foreign bodies, and foreign body aspiration are major causes of childhood mortality and morbidity, which are a big challenge to manage. In the US, more than 17,000 patients visited the emergency department with foreign body aspiration in 2008, and 220 children aged $<14$ years died due to foreign body aspiration in $2009^{1}$. In children younger than one year, airway obstruction by foreign bodies is the third most common cause of death due to unintentional injury ${ }^{1}$. In the US, 2900 deaths occur annually due to foreign body aspiration, as estimated by The National Safety Council ${ }^{2}$. Tracheal and bronchial foreign body obstruction is mainly seen among preschool children:- the most common is in infants and young children. More than $75 \%$ of cases due to the foreign body aspiration occur in children aged less than 3 years with $7 \%$ mortality rate ${ }^{3}$. In addition, foreign body aspiration is one of the major causes of infant and childhood mortality in developing countries $^{3}$. The greatest significance of our case is that it provides another possibility in diagnosis of endogenous foreign bodies and its treatment.

\section{Case presentation}

A one year boy with a history of cough and noisy breathing for 2 days was brought to Renmin Hospital with a sudden onset of difficulty in breathing and severe cough for 5 hours. He had no history of fever, no cold and no history of vomiting or choking. Bowel and bladder habits were normal. He had no significant past medical history. The patient had normal birth history, normal growth, and immunization was up to date. At the time of presentation he was conscious but restless and had difficulty in breathing: more so for inspiration. He had a bluish discoloration of lips, and was pale, but not icteric. He had no signs of dehydration and had no any palpable lymph node. At the time of presentation his vital sign readings were: HR 186 bpm (90-140bpm), RR 46/min (22-37/min), BP 78/40 MmHg (86-106/42-63 MmHg), temp $36.9^{\circ} \mathrm{C}\left(34.7-37.3^{\circ} \mathrm{C}\right.$ axillary) and SPO2 68\% (95-98\%). The throat was hyperemic, grade II enlargement of tonsils with congestion, but no pus point was noted. Chest examination showed bilateral symmetrical chest movement with intercostal retractions.
On auscultation there was decreased air entry on the right lung, with wheezing. Heart sounds were not distinct. The abdomen was soft, non-tender. There was no sign of meningitis. Consequently, the patient was initially diagnosed with acute laryngitis with bronchial pneumonia.

As there was history of sudden onset of difficulty in breathing, severe cough, inspiratory dyspnea and decrease air entry on the right lung, we planned for a CT scan of the chest. By this time the patient had been given oxygen, IV fluids, continuous ECG and SPO2 monitoring and nebulization with ipratropium bromide $(0.02 \% / 2.5 \mathrm{ml})$, albuterol $(0.05 \mathrm{mg} / \mathrm{kg})$, normal saline $(2 \mathrm{ml})$ and budesonide $(0.5 \mathrm{mg} / 2 \mathrm{ml})$. Intravenous methyl prednisolone $(2 \mathrm{mg} / \mathrm{kg} /$ day) was given and antibiotic Meropenem $(50 \mathrm{mg} / \mathrm{kg} /$ day $)$ was started. Routine blood investigations, along with ABG and throat swab cultures were performed. All other investigations were within normal limits, except for ABG: $\mathrm{pH} 7.25$ (7.35-7.45), Pao2 $70 \mathrm{mmHg}(75-100 \mathrm{mmHg}), \mathrm{PaCO} 255 \mathrm{mmHg}(35-45 \mathrm{mmHg})$, $\mathrm{HCO} 314.9 \mathrm{mmol} / \mathrm{L}(23-31 \mathrm{mmol} / \mathrm{L})$. There was little increase in WBC count $12.93 \times 10^{9} / \mathrm{L}\left(4-10 \times 10^{9} / \mathrm{L}\right)$, Neutrophils $69.4 \%$ (50-75\%), Lymphocytes 26\% (37-52\%), Monocytes 2.6\%(3-8\%) , Eosinophils $1.9 \%(0.5-5 \%)$, Basophils $0.1 \%(0-1 \%)$, and $\mathrm{Hb}$ $115 \mathrm{gm} / \mathrm{L}(110-150 \mathrm{gm} / \mathrm{L})$.

After one and half hours, the patient showed little improvement, and his vital signs were: HR 168 bpm, RR 40/min, BP 76/38 MmHg and SPO2 90\% with oxygen via mask. He was continuously on oxygen, IV fluids at maintenance dose, and frequent nebulization with Albuterol $(0.05 \mathrm{mg} / \mathrm{kg}$ TID), ipratropium bromide $(0.02 \% / 2.5 \mathrm{ml}$ TID), budesonide $(0.5 \mathrm{mg} / 2 \mathrm{ml}$ BID), and normal saline. Dopamine $(5 \mathrm{mcg} / \mathrm{kg} / \mathrm{min})$ and Dobutamine $(2 \mathrm{mcg} / \mathrm{kg} / \mathrm{min})$ was started on low dose to improve blood circulation. A CT scan of chest was performed that showed increased right lung volume and increased transparency of lung field. A soft tissue density shadow was observed in the right main bronchus blocking the lumen (Figure 1). The trachea was shifted slightly to the left, but no obvious abnormity was seen. The chest CT was suggestive of the presence of a right bronchial foreign body, with right sided obstructive emphysema.

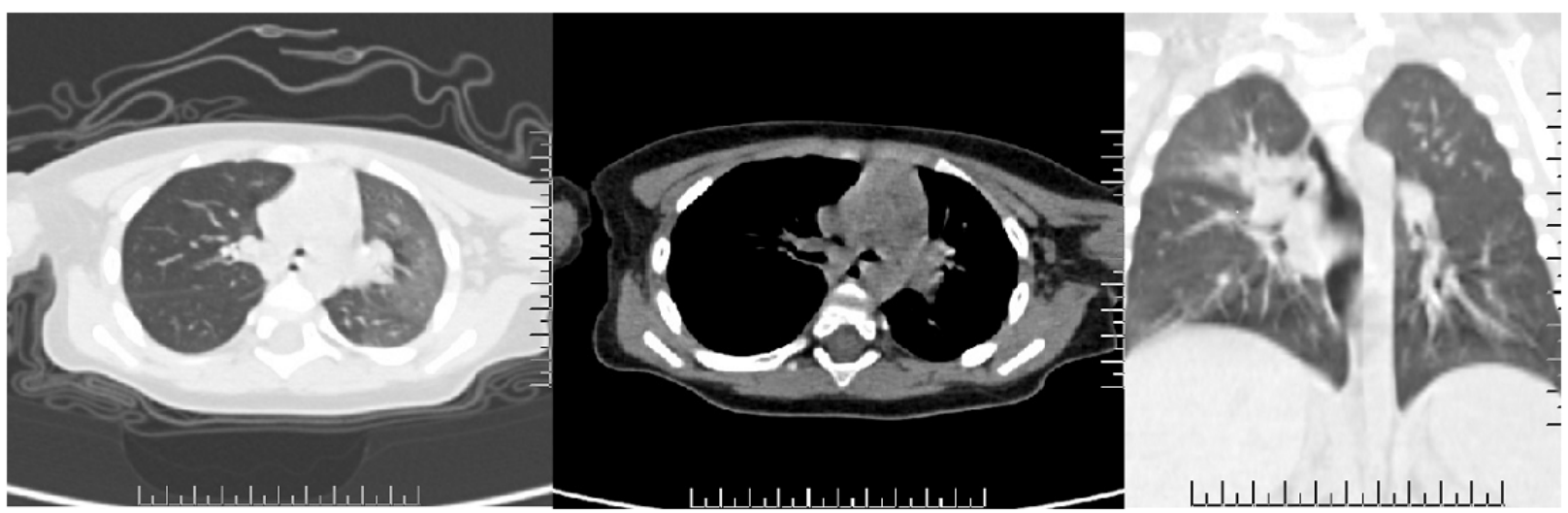

Figure 1. CT scan of the chest showing increased right lung volume and increased transparency of lung field. There is soft tissue density shadow seen in the right main bronchus blocking the lumen. The trachea is shifted slightly to the left, but no obvious abnormity is seen. The chest CT was suggestive of right bronchial foreign body, with right sided obstructive emphysema. 
After the CT scan, a consultation with the Consultant of Otolaryngology and Pulmonologist occurred. The consultant changed the diagnosis to right main bronchus foreign body obstruction probably due to mucus plug, and advised the possible need of a laryngeal mask airway or tracheal intubation, mechanical ventilation and bronchoscopic examination under anesthesia. However, the child was improving gradually, and was much calmer than before, with the exception of noisy breathing with an occasional cough. The patient started feeding after nine hours. The patient's heart rate decreased to $130 \mathrm{bpm}$ RR 36/min and SPO2 $92 \%$ with oxygen. On auscultation there was $\mathrm{b} / \mathrm{l}$ conducted sound with wheezing on the right lung. Repeat ABG was pH 7.34, Pao2 85mmHg, PaCO2 $46 \mathrm{mmHg}, \mathrm{HCO} 323.9 \mathrm{mmol} / \mathrm{L}$. Methyl prednisolone $(2 \mathrm{mg} / \mathrm{kg} /$ day OD) was continued and the antibiotic was switched to Cefotaxime $(100 \mathrm{mg} / \mathrm{kg} /$ day $\mathrm{q} 12 \mathrm{hr})$. Nebulization was continued and oxygen was given as needed. An additional CT scan of the chest was performed, which showed the infection of the right upper lobe and a narrow right upper lobe bronchus (Figure 2).

The patient improved gradually and was on same treatment for seven days. Then he was discharged on tapering dose of oral prednisolone. He has not any complained of cough or shortness of breath and chest is clear on auscultation on his follow up after 2 weeks.

\section{Discussion}

Aspiration of a foreign body in the airway mostly occurs in children younger than 15 years; children aged 1-3 years are the most susceptible. Foreign bodies can be exogenous, such as substances inhaled through the mouth (vegetables are the most common airway foreign body); the most common food item that are aspirated are peanuts. In young children, there is lack of molars for proper grinding of food and lack of coordination for swallowing and glottic closure, which is why they are most common age group for foreign body aspiration. Flexible fibro-optic bronchoscopy remains the gold standard for diagnosis and rigid bronchoscopy is the modality of choice in extracting airway foreign bodies $^{4}$. Endogenous foreign bodies are thick mucus or sputum, bronchial casts, dry scabs, blood clots, pus etc. Endogenous sources may also obstruct airways in same the way as plastic bronchitis ${ }^{5}$. Plastic bronchitis is a rare disorder, in which there is the presence of gelatinous or rubbery bronchial casts that may be coughed up or found at bronchoscopy or in surgical specimens. Although the pathophysiology is not clearly understood, it is commonly seen in children with congenital heart diseases, cardiac and pericardial diseases in adults and in patients with chronic asthma ${ }^{6}$. Plastic bronchitis is more common in the lower lobe, but it may also occur in any segments of the bronchial tree ${ }^{7}$. As plastic bronchitis is common in the lower lobe, it is different to mucoid impaction, which tends to occur in the large segmental bronchi of the upper lobe; they are generally tightly adherent to the wall, and they are retained rather than being expectorated ${ }^{7}$. Mucoid impaction has a strong correlation with asthma ${ }^{8}$.

Children cannot cough out the sputum completely. When there is an infection, the glands on the respiratory passage secrete large amounts of mucous and debris, which lead to blockage of respiratory bronchioles and bronchus. This can later develop the symptoms similar to the foreign body obstruction. In the present case, the child presented with symptoms mimicking foreign body obstruction, but the clinical history was not suggestive. Imaging suggested a bronchial foreign body obstruction. By that time the patient's symptoms were gradually improving by repeated nebulization with normal saline mix with Albuterol and Ipratropium bromide and steroids. This showed us that the sputum may sometimes block the respiratory passage and mimic foreign body bronchial obstruction. In this case we avoided fiberoptic bronchoscopy in order to reduce pain and risk during procedure, as well as reduce medical costs. A limitation in this case was that it is not fully clear whether it was foreign body or blockage due to sputum plug. Post treatment observation is necessary in such a condition. If the block is above the tracheobronchial bifurcation, the child obviously lacks $\mathrm{O}_{2}$ and

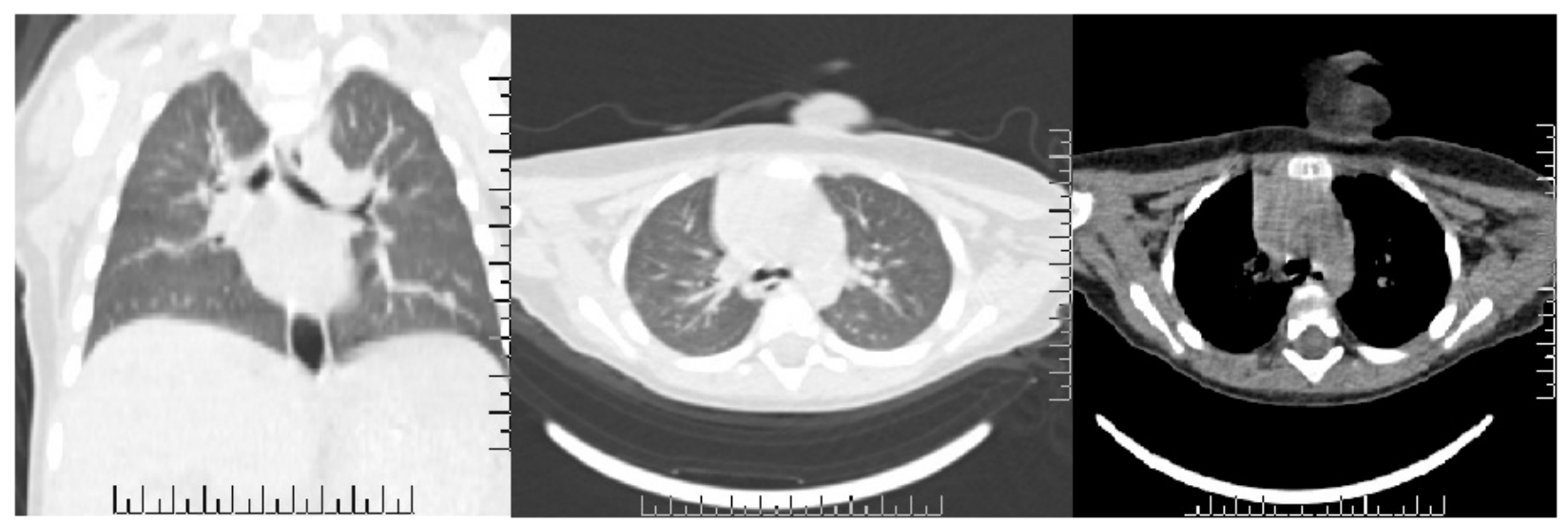

Figure 2. Repeat CT scan of the chest showing infection of the right upper lobe and narrow right upper lobe bronchus. 
it should be removed immediately by fiberoptic bronchoscope. If the block is below the tracheobronchial bifurcation, the patient can be treated conservatively and observed. Mucolytic agents, like $\mathrm{N}$ - Acetyl Cysteine, could have also been used. Salamone et al. (2017) published a case report where they mechanically removed bronchial tree-shaped mucous plug in a cystic fibrosis patient 9 . Park et al. mentioned that mucus impaction and plastic bronchitis are usually self-limited or responsive to medical therapy, with a good prognosis, although their patient did not respond to oral corticosteroid or intrabronchial instillation of acetylcysteine and continued to deteriorate despite medical therapy ${ }^{8}$.

\section{Conclusion}

Symptoms resembling solid foreign body obstruction are not always aspirated or inhaled. Sometimes secreted sputum forming a plug also mimics the symptoms of foreign body obstruction. If there is no clear history of foreign body ingestion or aspiration of gastric content, immediate nebulization may help greatly.

\section{Consent}

We have taken written informed consent from the child's legal guardian (his Mother) to use her child's medical case history for the publication of this article.

\section{Competing interests}

No competing interests were disclosed.

\section{Grant information}

The author(s) declared that no grants were involved in supporting this work.

\section{Acknowledgements}

We wish to thank Li Yan, Nursing Chief and entire doctor and nursing staffs of Department of Pediatrics, Renmin Hospital, and to the child's parents for the consent.
1. National Safety Council: Injury, Death and Fatality Statistics. 2013

National Safety Council: Accident Facts. 1992; 32.

Yetim TD, Bayarogullari $\mathrm{H}$, Arica V, et al:: Foreign Body Aspiration in Children; Analysis of 42 Cases. J Pulmon Resp Med. 2012; 2: 121. Publisher Full Text

4. Sahil AM, Alfaki M, Alam-Elhuda DM: Airway foreign bodies: A critical review for a common pediatric emergency. World J Emerg Med. 2016; 7(1): 5-12. PubMed Abstract | Publisher Full Text | Free Full Text

5. Alfageme I, Reyes N, Merino M: Aspirated foreign body. Int J Pulmon Med. 2007; 7: 5-6.

6. Webb WA: Management of foreign bodies of the upper gastrointestinal tract: update. Gastrointest Endosc. 1995; 41(1): 39-51. PubMed Abstract | Publisher Full Text

7. Somani SS, Naik CS: Bronchial cast: a case report. Indian J Otolaryngol Head Neck Surg. 2008; 60(3): 242-244.

PubMed Abstract | Publisher Full Text | Free Full Text

8. Park JY, Elshami AA, Kang DS, et al.: Plastic bronchitis. Eur Respir J. 1996; 9(3): 612-614.

PubMed Abstract | Publisher Full Text

9. Salamone I, Mondello B, Lucanto MC, et al.: Bronchial tree-shaped mucous plug in cystic fibrosis: imaging-guided management. Respirol Case Rep. 2017; 5(2): e00214.

PubMed Abstract | Publisher Full Text | Free Full Text 


\section{Open Peer Review}

\section{Current Peer Review Status:}

\section{Version 1}

Reviewer Report 23 March 2018

https://doi.org/10.5256/f1000research.13529.r31882

(C) 2018 Hu P. This is an open access peer review report distributed under the terms of the Creative Commons Attribution License, which permits unrestricted use, distribution, and reproduction in any medium, provided the original work is properly cited.

\section{Peng Hu}

Department of Pediatrics, The First Affiliated Hospital of Anhui Medical University, Hefei, China

Author has made good case report- Mucus plug in bronchus mimicking a bronchial solid foreign body obstruction. We often encounter a child with sudden shortness of breath on emergency department which after nebulization get stable. It would be better if they have done bronchoscopic examination. This case report helps to think other clinician that mucus plug can cause obstruction.

Author describes the case history, clinical presentation and management in detail. I feel there is space to discuss more on obstruction by other agents.

I hope this case report is good and help to other clinician as well.

Is the background of the case's history and progression described in sufficient detail? Yes

Are enough details provided of any physical examination and diagnostic tests, treatment given and outcomes?

Yes

Is sufficient discussion included of the importance of the findings and their relevance to future understanding of disease processes, diagnosis or treatment? Partly

Is the case presented with sufficient detail to be useful for other practitioners? Yes

Competing Interests: No competing interests were disclosed.

I confirm that I have read this submission and believe that I have an appropriate level of 
expertise to confirm that it is of an acceptable scientific standard.

Author Response 23 Mar 2018

Kiran Devkota, Renmin Hospital, Shiyan, China

Respected Hu Peng

Thank you so much for your review and valuable suggestion.

My best regards

Kiran Devkota

Competing Interests: No competing interests were disclosed.

Reviewer Report 23 March 2018

https://doi.org/10.5256/f1000research.13529.r32198

(C) 2018 Menzella F. This is an open access peer review report distributed under the terms of the Creative Commons Attribution License, which permits unrestricted use, distribution, and reproduction in any medium, provided the original work is properly cited.

\section{Francesco Menzella}

Department of Medical Specialties, Pneumology Unit, Arcispedale Santa Maria Nuova - IRCCS, Reggio Emilia, Italy

The case is well described and interesting. I have only a few minor observations:

On page 3, line 1 and 2, consultant and consultation is repeated several times: I would also use synonyms to avoid repeating the same words

At least the use of some acronyms must be explicitly expanded, eg ABG, BP, HR

Line 11 page 3: "b / I" must be written in full

Is the background of the case's history and progression described in sufficient detail? Yes

Are enough details provided of any physical examination and diagnostic tests, treatment given and outcomes?

Yes

Is sufficient discussion included of the importance of the findings and their relevance to future understanding of disease processes, diagnosis or treatment?

Yes 
Is the case presented with sufficient detail to be useful for other practitioners?

Yes

Competing Interests: No competing interests were disclosed.

I confirm that I have read this submission and believe that I have an appropriate level of expertise to confirm that it is of an acceptable scientific standard.

\section{Author Response 23 Mar 2018}

Kiran Devkota, Renmin Hospital, Shiyan, China

Respected Francesco Menzella

I am very grateful to you. Thank you so much for reveiw and valuable suggestion.

My best regards

Kiran Devkota

Competing Interests: No competing interests were disclosed.

The benefits of publishing with F1000Research:

- Your article is published within days, with no editorial bias

- You can publish traditional articles, null/negative results, case reports, data notes and more

- The peer review process is transparent and collaborative

- Your article is indexed in PubMed after passing peer review

- Dedicated customer support at every stage

For pre-submission enquiries, contact research@f1000.com 